\title{
Health status of primary schoolchildren in Sri Lanka
}

\author{
A Pathmeswaran ${ }^{1}$, R Jayatissa ${ }^{2}$, S Samarasinghe ${ }^{3}$, A Fernando ${ }^{4}$, RP de Silva ${ }^{5}$, \\ RO Thattil ${ }^{6}$ and NR de Silva ${ }^{7}$
}

(Index words: Anaemia, goitre, malnutrition, soil-transmitted nematode infection, vision)

\begin{abstract}
Objective To assess health status of 9-10-year old school children in Sri Lanka.

Design A cross-sectional, descriptive study. Schools were selected to obtain a sample representative at national and provincial levels and 20 children were randomly selected from Grade 5 classes in each school.

Measurements Children were examined for Bitot's spots and goitre. Height, weight, and visual acuity were measured according to standard procedures. Haemoglobin level was measured using finger-prick blood and a HemoCue ${ }^{\circledR}$ meter. Geohelminth infections were quantified by faecal examination using the modified Kato-Katz technique. Height for age Z-scores (HAZ) and body mass index (BMI) were calculated as indicators of nutritional status.

Results Two thousand five hundred and twenty eight children (1351 boys) from 144 schools (140 state schools and four private schools) were examined. Nationally, $15.5 \%$ of children were stunted (HAZ lower than $-2.0 \mathrm{SD}$ ); $52.6 \%$ were thin $(\mathrm{BMI}<5$ th centile of age- and sexmatched reference population); $3.1 \%$ were overweight (BMI > 85th centile); $12.1 \%$ were anaemic; $0.3 \%$ had Bitot's spots; $3 \%$ had a visible or palpable goitre; $4.6 \%$ were shortsighted; and $6.9 \%$ had one or more soil-transmitted nematode infection. Among children on whom anthropometry, haemoglobin and faecal examinations were all done, $64.6 \%(1332 / 2063)$ were thin, stunted, anaemic or infected with worms. A much higher proportion of children in the Northern and Eastern provinces had health problems when compared to the other provinces.

Conclusions The majority of older primary schoolchildren in Sri Lanka are undernourished. Anaemia, vitamin A deficiency, iodine deficiency and soil-transmitted nematode infections affect a much smaller proportion of them.
\end{abstract}

\section{Introduction}

Sri Lanka has achieved near-universal, genderequitable, access to primary education [1]. It now needs to focus on the quality of education offered to its children. Problems with nutrition and health can limit opportunity for children to participate in school activities and diminish their ability to learn and progress once enrolled [2]. The main nutritional problems of school-age children in most developing countries include stunting, underweight, anaemia, iodine deficiency and vitamin A deficiency, and the health problems include malaria, helminth infection, diarrhoeal diseases, respiratory infections and direct or indirect effects of HIV/AIDS. In countries experiencing 'nutrition transition', problems of overweight and obesity are increasing [3].

During the last few years, it has become increasingly recognised that more attention should be paid to the health needs of schoolchildren [4]. However, school health policies that have been developed for most low income tropical countries may not be directly applicable to Sri Lanka. Although the country has barely achieved middle income status, its performance in health and education is very different from those of most developing countries [5].

This paper describes a survey that was done among primary schoolchildren in Sri Lanka to assess health factors that could affect the achievements of these children. The survey was part of a larger study sponsored by the National Education Commission (NEC), that examined the relative importance of various factors, including health, that affects the learning achievements of schoolchildren in the primary schools of Sri Lanka.

\section{Methods}

\section{Sampling}

Children who had completed 4 years of schooling by the end of the year 2002, in schools following the national curriculum formed the study population. To derive a nationally representative sample, schools were first selected from among 9479 non-fee-levying, state-run schools that offered primary education, using multistage stratified sampling. In Stage 1, stratification was at provincial level, with representation of all the nine Provinces in the country. In Stage 2, stratification was by

${ }^{1}$ Department of Community Medicine, Faculty of Medicine, University of Kelaniya; ${ }^{2}$ Department of Nutrition, Medical Research Institute, Colombo; ${ }^{3}$ Department of Parasitology, Medical Research Institute, Colombo; ${ }^{4}$ Department of Paediatrics, Faculty of Medicine, University of Kelaniya; ${ }^{5}$ Department of Agricultural Engineering, Faculty of Agriculture, University of Peradeniya; ${ }^{6}$ Postgraduate Institute of Agriculture, University of Peradeniya; 'Department of Parasitology, Faculty of Medicine, University of Kelaniya.

Correspondence: AP, e-mail: <pathmes@eureka.lk> (Competing interests: none declared) Received 7 January 2005 and accepted 2 April 2005. 
functional type of school (the Ministry of Education recognises four functional types of schools, categorised according to the classes offered by the school). In Stage 3 , for each type of state-run school, schools from rural and urban areas were selected in proportion to the size of population in the Province. In addition, four (three in the Western and one in the Central Province), fee-levying private schools that also follow the national curriculum were selected from among 26 such schools in the country. Finally, in each selected school, 20 children were randomly selected from among those registered in Grade 5 in 2003. Where a school had less than 20 children on its register, the required numbers were drawn from the nearest school of the same type.

\section{Health survey}

The health survey was done during the period JuneSeptember 2003, by staff of the Medical Research Institute (MRI), Colombo. The field staff worked in five teams, each consisting of two Public Health Inspectors (PHI) and a microscopist. The PHIs were trained and experienced in assessing nutritional status, and the microscopists were trained in faecal examination for intestinal nematode eggs. Informed written consent was obtained from each child's parent or guardian for examination and for taking blood sample.

\section{Physical anthropometry}

Height was measured in centimetres to the nearest decimal, using an anthropometric rod. Weight was measured in kilograms to the nearest decimal, using an electronic weighing scale. Date of birth was obtained from school registers. Two indices were calculated for assessment of nutritional status: height-for-age Z-score (HAZ) and body mass index (BMI). The BMI was used as an indicator of 'thinness' rather than the weight-for-height Z-score. Children with HAZ scores lower than -2.0 SD were considered stunted. Children who had a BMI-forage below the 5 th centile of the age and sex-specific NCHS reference population, were categorised as 'thin', and those above the 85 th centile of the same reference population as 'overweight' [6].

\section{Anaemia}

Haemoglobin level was measured in $\mathrm{g} / \mathrm{dL}$, using $10 \mu \mathrm{L}$ of finger-prick blood and a HemoCue ${ }^{\circledR}$ meter, which is recommended as a reliable quantitative method for determining haemoglobin concentrations in field surveys. Sterile disposable lancets were used for drawing blood and all sterile precautions were followed. Children with a haemoglobin level below $11.5 \mathrm{~g} / \mathrm{dL}$ of blood were considered anaemic; this cut-off was adjusted as recommended by the WHO for those living at altitudes over $1000 \mathrm{~m}$ [7]

\section{Bitot's spots and goitre}

Both eyes were examined for the presence of Bitot's spots as clinical evidence of vitamin A deficiency. Each child was examined using the standard technique recommended for assessment of goitre status. Goitre status was categorised as Grade 0 (thyroid not palpable or visible), Grade 1 (thyroid palpable but not visible with neck in normal position), or Grade 2 (goitre visible with neck in normal position, and consistent with enlarged thyroid when neck is palpated), according to current WHO recommendations [8].

\section{Visual acuity}

Visual acuity was examined using a Snellen's chart with numerals, at a distance of $6 \mathrm{~m}$, for evidence of myopia. Where children had previously been found to have defective eyesight and were wearing corrective spectacles, testing was done with the glasses on. A child who had $6 / 6$ vision or $6 / 9$ vision in the better eye was considered to have normal visual acuity [9].

\section{Geohelminth infections}

Faecal samples were examined microscopically on the day of collection for eggs of hookworms, roundworms, and whipworms. The modified Kato-Katz method was used to quantify infection, as recommended by the WHO [10]. Kits were from Vestergaard-Frandsen, India.

\section{Other health related information}

The mother or other principal caretaker of each child was interviewed at home, with trained enumerators using a pre-tested questionnaire. Health related information recorded in this manner included any past history of malaria, any chronic illness that resulted in frequent absenteeism from school, and anthelmintic treatment given within the past year.

Examination of blood films for malaria was not carried out because malaria incidence in 2003 was low, and our survey was done during a non-malaria season. It was decided instead to use information on any past attacks of malaria, as provided by the child's principal caregiver. Hearing defects and psychological problems, which are also factors that could affect learning in school, were not assessed in this survey.

\section{Data entry and statistical analysis}

Data was entered using MS Access and analysed using EpiInfo 6.02. Prevalence rates were calculated for the nine Provinces and within these Provinces the rates for boys and girls were calculated separately. Statistical significance was assessed using the chi-square test and Fisher's exact test when the chi-square test was not appropriate. Because the fee-levying private schools generally draw children from a more affluent background 
than non-fee-levying schools, children from the four private schools were grouped together, separate from the state schools.

Approval for this study was obtained from the Ethical Review Committee of the Faculty of Medicine, University of Kelaniya.

\section{Results}

The survey included 2528 children from 144 schools. The mean age of the children was 9.6 years (range 9-15 years, SD 0.6 years). Their distribution by Province and sex is shown in Table 1.

Table 1. Distribution of study sample by province and sex

\begin{tabular}{lrrrrr}
\hline & \multicolumn{5}{c}{ Number examined } \\
Province & Boys & $\%$ & Girls & \multicolumn{1}{c}{$\%$} & Total \\
\hline Central & 112 & 40.6 & 164 & 59.4 & 276 \\
Eastern & 138 & 50.7 & 134 & 49.3 & 272 \\
North Central & 131 & 49.1 & 136 & 50.9 & 267 \\
North Western & 188 & 67.9 & 89 & 32.1 & 277 \\
Northern & 157 & 58.4 & 112 & 41.6 & 269 \\
Sabaragamuwa & 137 & 54.2 & 116 & 45.8 & 253 \\
Southern & 162 & 57.4 & 120 & 42.6 & 282 \\
Uva & 137 & 51.1 & 131 & 48.9 & 268 \\
Western & 153 & 51.2 & 146 & 48.8 & 299 \\
Private schools & 36 & 55.4 & 29 & 44.6 & 65 \\
Sri Lanka & $\mathbf{1 3 5 1}$ & $\mathbf{5 3 . 6}$ & $\mathbf{1 1 7 7}$ & $\mathbf{4 6 . 4}$ & $\mathbf{2 5 2 8}$ \\
\hline
\end{tabular}

\section{Malnutrition}

The proportions of children who were stunted are shown in Table 2. In the state schools, the rates ranged from $12.0 \%$ in the North Western Province to $20.2 \%$ in the Eastern Province. None of the children attending private schools were stunted. The national prevalence was $15.5 \%$. The differences between boys and girls were not statistically significant, except in the North Central Province, where

Table 2. Indicators of malnutrition by province

\begin{tabular}{lcccc}
\hline Province & $\begin{array}{c}\text { HAZ } \\
\text { Stunted } \\
(\%)\end{array}$ & $\begin{array}{c}\text { Thin } \\
(\%)\end{array}$ & $\begin{array}{c}\text { Bodymass index } \\
\text { Normal }\end{array}$ & $\begin{array}{c}\text { Overweight } \\
(\%)\end{array}$ \\
\hline Central & 17.0 & 55.4 & 42.8 & 1.8 \\
Eastern & 20.2 & 53.5 & 43.5 & 3.0 \\
North Central & 13.5 & 53.2 & 43.4 & 3.4 \\
North Western & 12.0 & 50.2 & 45.1 & 4.7 \\
Northern & 18.2 & 52.8 & 45.7 & 1.5 \\
Sabaragamuwa & 16.3 & 56.1 & 42.3 & 1.6 \\
Southern & 17.5 & 53.5 & 42.9 & 3.5 \\
Uva & 17.0 & 54.5 & 44.8 & 0.7 \\
Western & 12.4 & 52.8 & 43.8 & 3.3 \\
Private schools & 0.0 & 16.9 & 61.5 & 21.5 \\
Sri Lanka & $\mathbf{1 5 . 5}$ & $\mathbf{5 2 . 6}$ & $\mathbf{4 4 . 3}$ & $\mathbf{3 . 1}$ \\
\hline
\end{tabular}

HAZ-Height for age Z-score. more boys than girls were stunted (25/131 vs 11/136, chisquare $=6.92, \mathrm{P}=0.01$ ). Table 2 also shows the distribution of BMI values. About half of those attending state schools (50.2-56.1\%), fell into the category 'thin'. Again, the differences between boys and girls were not statistically significant except in one Province, Uva, where significantly more boys than girls were 'thin' (88/135 vs 58/ 131 , chi-square $=11.7, \mathrm{P}<0.001)$. In the four private schools, the proportion of 'thin' children was only $16.9 \%$, whereas $21.5 \%$ of children were 'overweight'. The national average prevalence of overweight was $3.1 \%$.

\section{Anaemia}

Finger-prick blood for estimation of haemoglobin level was obtained only from children who had the written permission of a parent or guardian. Table 3 shows the prevalence of anaemia by Province. The difference in the prevalence of anaemia between girls and boys was not statistically significant except in Uva, where significantly more girls than boys were anaemic. The national prevalence of anaemia was $12.1 \%$. The prevalence of anaemia among children who were stunted in growth was slightly higher than among those who were not stunted (50/326, 15.3\% vs $202 / 1737,11.6 \%$ ) but this difference was not statistically significant (chi-square $=3.52, \mathrm{P}=0.06$ ).

Table 3. Mean haemoglobin level and prevalence of anaemia by province

\begin{tabular}{lcccrr}
\hline Province & \multicolumn{2}{c}{$H b(\mathrm{~g} / \mathrm{dL})$} & \multicolumn{3}{c}{ Percentage anaemic } \\
(number examined $\left.{ }^{*}\right)$ & Mean & \multicolumn{1}{c}{$S D$} & Boys & Girls & Total \\
\hline Central $(\mathrm{n}=269)$ & 13.1 & 0.96 & 8.3 & 5.0 & 6.3 \\
Eastern $(\mathrm{n}=272)$ & 12.4 & 0.99 & 14.5 & 12.7 & 13.6 \\
North Central $(\mathrm{n}=264)$ & 12.5 & 1.01 & 10.0 & 11.9 & 11.0 \\
North Western $(\mathrm{n}=275)$ & 12.5 & 1.01 & 14.4 & 20.5 & 16.4 \\
Northern $(\mathrm{n}=268)$ & 11.9 & 1.21 & 31.8 & 23.2 & 28.3 \\
Sabaragamuwa $(\mathrm{n}=250)$ & 12.7 & 0.97 & 11.1 & 7.8 & 9.6 \\
Southern $(\mathrm{n}=279)$ & 12.7 & 0.97 & 7.5 & 11.9 & 9.3 \\
Uva $(\mathrm{n}=267)$ & 13.0 & 1.09 & $5.1^{* *}$ & $12.2^{* *}$ & 8.6 \\
Western $(\mathrm{n}=298)$ & 12.8 & 0.97 & 7.8 & 6.9 & 7.4 \\
Private schools $(\mathrm{n}=42)$ & 12.8 & 0.76 & 0.0 & 3.7 & 2.4 \\
Sri Lanka $(\mathbf{n}=\mathbf{2 4 8 5})$ & $\mathbf{1 2 . 6}$ & $\mathbf{1 . 0 6}$ & $\mathbf{1 2 . 5}$ & $\mathbf{1 1 . 6}$ & $\mathbf{1 2 . 1}$ \\
\hline
\end{tabular}

* Blood sample was taken only from children who had written permission of a parent or the guardian.

$* *$ Statistically significant difference: chi-square $=4.23, \mathrm{P}=0.04$

\section{Vitamin A deficiency and goitre}

The prevalence of clinically obvious vitamin A deficiency was low: only $0.3 \%$ of the children had Bitot's spots ( $0.4 \%$ of boys and $0.2 \%$ of girls). The prevalence of visible or palpable enlargement of the thyroid gland was also low (3\%). Prevalence rates among girls was significantly higher than among boys (57/1177 vs 23/1351, chi-square $=20.3, \mathrm{P}<0.001$ ). 


\section{Visual acuity}

The prevalence of shortsightedness in the state schools ranged from $2.8 \%$ in Sabaragamuwa to $7.1 \%$ in the North Central Province. It was $7.7 \%$ in the private schools, and the national average was $4.6 \%$. Again, there was no significant difference between boys and girls, except in the private schools, where more boys than girls were found to be shortsighted (5/36 vs 0/29, Fisher's exact P-value $=0.04)$.

\section{Geohelminth infection}

Estimation of the prevalence of ascariasis, trichuriasis and hookworm infection was based on the examination of 2162 stool samples provided by the children. As shown in Table 4 , the national prevalence of each infection was less than $5 \%$, with a cumulative prevalence of $6.9 \%$ for all three infections. There were no differences in its prevalence between boys and girls. Almost all infections were of low intensity. According to the information gathered from the children's principal caregivers, 8.9\% (238/2688) had passed worms (probably roundworms) at some time in their lives. Islandwide, $90 \%$ of all children had been given some form of anthelmintic treatment during the previous year.

\section{Malaria and chronic illnesses}

Only $6.4 \%$ (171 / 2688) children were reported to have had malaria attacks in the past. As expected from knowledge of the current distribution of endemic malaria in Sri Lanka, there were marked regional differences in occurrence. Only $1 \%$ of the children in the Central, Sabaragamuwa and Western Provinces (which are largely non-endemic) had ever had malaria, whereas in the Northern Province $28 \%$ of the children were reported to have had experienced malaria at some time in their lives.

About 15\% (406/2686) of the children were reported to experience frequent illnesses that led to their absence from school. The most common identified causes were 'fevers' $(\mathrm{n}=170)$, followed by asthma or recurrent wheezing $(n=70)$.

\section{Discussion}

This is the first nationally representative study that has comprehensively assessed physical health problems in Sri Lankan schoolchildren. Nationally, we found that about $15 \%$ of the children were stunted. This result is

Table 4. Prevalence of soil-transmitted helminth infections

\begin{tabular}{lcccc}
\hline $\begin{array}{l}\text { Province } \\
\text { Number examined }\end{array}$ & Pookworm & $\begin{array}{c}\text { Percentage positive for eggs of } \\
\text { Roundworm }\end{array}$ & Whipworm & Cumulative prevalence \\
\hline Central $(\mathrm{n}=190)$ & 0.0 & 4.1 & 4.7 & 8.8 \\
Eastern $(\mathrm{n}=261)$ & 5.7 & 2.3 & 6.9 & 12.3 \\
North Central $(\mathrm{n}=237)$ & 0.4 & 1.7 & 0.0 & 2.1 \\
North Western $(\mathrm{n}=256)$ & 0.0 & 0.8 & 5.1 & 5.4 \\
Northern $(\mathrm{n}=243)$ & 4.1 & 4.5 & 3.7 & 11.1 \\
Sabaragamuwa $(\mathrm{n}=228)$ & 0.0 & 2.2 & 3.5 & 3.9 \\
Southern $(\mathrm{n}=236)$ & 0.0 & 0.4 & 1.2 & 1.6 \\
Uva $(\mathrm{n}=208)$ & 0.0 & 5.3 & 1.4 & 6.7 \\
Western $(\mathrm{n}=281)$ & 0.3 & 4.3 & 0.5 & 10.0 \\
Private schools $(\mathrm{n}=33)$ & 0.0 & 0.0 & 0.0 & 0.0 \\
Total $(\mathbf{n}=\mathbf{2 1 7 3})$ & $\mathbf{1 . 2}$ & $\mathbf{2 . 8}$ & $\mathbf{4 . 0}$ & $\mathbf{6 . 9}$ \\
\hline
\end{tabular}

* Overall $86 \%$ of children brought stool sample for examination

Children infected with any one or more geohelminth had a significantly higher prevalence of anaemia than those who were uninfected $(28 / 134,20.9 \%$ vs $224 / 1929$, $11.6 \%$; chi-square $=10.07, \mathrm{P}=0.001)$. There was, however, no significant association between geohelminth infection and stunting of growth $(23 / 134,17.2 \%$ vs $303 / 1626,15.7 \%$, chi-square $=0.2, \mathrm{P}=0.6$ )

In 2063 children in whom anthropometry, haemoglobin and faecal examinations were all done, 1332 $(64.6 \%)$ were thin, stunted, anaemic or infected with geohelminths. The rates were highest in the Northern and Eastern Provinces, where $76.6 \%$ and $74.6 \%$ of the children, respectively, had one or more problems. similar to that found in under-fives in the national Demographic and Health Survey of 2000 [11], but somewhat less than the prevalence of $22.6 \%$ found in a study of 15120 schoolchildren (aged 5-14 years) done by the MRI in 23 districts in years 2001-2003 (Jayatissa, unpublished data). The prevalence of thinness, diagnosed on the basis of age- and sex-based BMI was $52 \%$, and only $3.2 \%$ were overweight or obese. Such high rates of thinness could mean that the cut-off values are inappropriate for Sri Lankan children, or that they are a result of late maturation, with a delay in the growth spurt in Sri Lankan children when compared to the US reference population.

The national prevalence of anaemia was about $12 \%$, which is less than the $20.7 \%$ found in a survey that covered 
2438 children of a comparable age group (5-11 year olds) in seven of the nine Provinces of Sri Lanka in 2001 [12]. The prevalence of anaemia has been declining in general [12]. Clinical evidence of other micronutrient deficiencies, as indicated by the prevalence of Bitot's spots (0.3\%) and goitre (3\%), was low.

The prevalence of geohelminth infection and malaria, which are often a major problem in schoolchildren in other developing countries, were also low. The cumulative prevalence of geohelminth infection was $6.9 \%$, and only $6.4 \%$ of children had a lifetime history of malaria. The prevalence of geohelminth infection may be an underestimate. In several Provinces, the household interviews were conducted some days before the medical examination of the children, and the children had been given anthelmintics soon after the interview. Almost all parents said that they de-wormed their children regularly, a claim supported by the finding that in many areas, the prevalence of trichuriasis was higher than that of ascariasis, a well-known inversion of the natural epidemiology of the two infections, resulting from widespread use of wide-spectrum anthelmintics.

Frequent illness, sufficient to prevent the child from attending school, was reported in $15 \%$ of the study population; the commonest identified problems were fevers and asthma. Shortsightedness affected about 5\% of the children. In general, children attending private schools have fewer problems with health and nutrition, when compared with those in the state sector; the only exception being the higher prevalence of overweight and shortsightedness. When comparing the health status of children in different provinces, a much higher proportions of children in the Northern Province and in the Eastern Province, have problems. This is almost certainly a result of two decades of violent conflict in these areas.

\section{Acknowledgements}

We thank Professor RP Gunawardane and Mr. Anura Hettiarachchi at the NEC for their constant support; Director General Health Services and the Director, Medical Research Institute for permission to perform the study; the members of the field survey teams for the technical work; MG Consultants (Pvt) Ltd for carrying out the household survey; and all the children who participated most willingly in the survey.

This study was commissioned by the National Education Commission, with financial support from the World
Bank-General Education Project 2 of the Ministry of Education.

\section{References}

1. Ministry of Human Resource Development, Education and Cultural Affairs, Government of Sri Lanka. School Census 2003: preliminary report.

2. Bergeron G, Del Rosso JM. Food for Education Indicator Guide. Washington: Food and Nutrition Technical Assistance Project, Academy for Educational Development, 2001.

3. United Nations, Administrative Committee on Coordination, Sub-committee on Nutrition (ACC/SCN). Fourth Report on the World Nutrition Situation: Nutrition throughout lifecycle. Geneva: ACC/SCN in collaboration with International Food Policy Research Institute (IFPRI), January 2000.

4. The Partnership for Child Development. Better health, nutrition and education for the school-aged child [editorial]. Transactions of the Royal Society of Tropical Medicine and Hygiene 1997; 91: 1-2.

5. Pathmanathan I, Liljestrand J, Martins JM, Rajapaksa LC, Lissner C, et al. Investing in Maternal Health. Learning from Malaysia and Sri Lanka. Washington: The World Bank, 2003.

6. World Health Organisation. Physical status: the use and interpretation of anthropometry. WHO Technical Report Series Number 854. Geneva: World Health Organisation, 1995.

7. World Health Organisation. Iron deficiency anaemia: assessment, prevention and control. Geneva: World Health Organisation; 2001 (WHO / NHD / 01.3).

8. World Health Organisation. Indicators for assessing iodine deficiency disorders and their control through salt iodization. Geneva: WHO in collaboration with UNICEF and ICCIDD; 1994 (WHO / NUT / 94.6).

9. Polnay L, Hull D. Community Paediatrics. Edinburgh: Churchill Livingstone, 1985.

10. Montresor A, Crompton DWT, Gyorkos TW, Savioli L. Helminth control in school-age children: a guide for managers of control programmes. Geneva: World Health Organisation, 2002.

11. Department of Census and Statistics. Demographic and Health Survey Sri Lanka 2000: preliminary report. Colombo, Ministry of Finance and Planning in collaboration with Ministry of Health, 2001.

12. Medical Research Institute. Assessment of anaemia status in Sri Lanka 2001. Colombo: Medical Research Institute, 2002. 